amides and by the position of substituents in atomatic amides.

3. Experiments with typical aliphatic, $\omega$-phenylsubstituted aliphatic and aromatic amides suggest that the same amidase is concerned with the hydrolysis of all the amides. $8 \cdot 4$.

4. The amidase is most effective between $\mathrm{pH} 8 \cdot 2$
We wish to make grateful acknowledgement to Prof. T. P. Hilditch, F.R.S., who provided the ethyl hendecanoate and $n$-tetradecanol for the preparation of hendecanamide and pentadecanamide. We have to thank Mr P. B. Wood for assistance in the preparation of some of the amides. We are indebted to the Royal Society for a Government Grant which defrayed part of the cost of this work. The micro-analyses were carried out by Drs Weiler and Strauss, Oxford.

\title{
REFERENCES
}

Baeyer, A. \& Jackson, O. R. (1880). Ber. dtsch. chem. Ges. 13, 122.

Borsche, W. (1919). Ber. dtsch. chem. Ges. 52, 2084.

Borsche, W. \& Wollemann, J. (1912). Ber. dtsch. chem. Ges. 45, 3713.

Bray, H. G., James, S. P., Raffan, I. M., Ryman, B. E. \& Thorpe, W. V. (1949a). Biochem. J. 44, 618.

Bray, H. G., James, S. P., Ryman, B. E. \& Thorpe, W. V. (1948). Biochem. J. 42, 274.

Bray, H. G., James, S. P., Thorpe, W. V., Wasdell, M. R. \& Wood, P. B. $(1949 b)$. Biochem. J. 45, 467.

Bray, H. G., Thorpe, W. V.\& Wood, P. B. $(1949 c)$. Biochem. $J .45,45$.

Dippy, J. F. J. \& Williams, F. R. (1934). J. chem. Soc. p. 1466.
Forbes, J. C. (1927). J. biol. Chem. 71, 559.

Geddes, W. F. \& Hunter, A. (1928). J. biol. Chem. 77, 197.

Hunter, A. \& Downs, C. E. (1944). J. biol. Chem. 155, 173.

Overbaugh, S. C., Allen, C. F. H., Martin, E. L. \& Fieser, L. F. (1935). Organic Synth. 15, 64.

Perkin, W. H. (1877). J. chem. Soc. p. 388.

Schiemann, G. \& Winkelmüller, W. (1933). Organic Synth. 13, 52.

Somerville, L. F. \& Allen, C. F. H. (1933). Organic Synth. $13,12$.

Somerville, L. F. \& Allen, C. F. H. (1935). Organic Synth. 15, 92.

Vanino, L. (1923). Handbuch der präparativen Chemie, 2nd ed. Vol. 2, p. 591. Stuttgart: Enke.

\section{Determination of Antrycide}

\author{
By A. SPINKS \\ Imperial Chemical Industries Research Laboratories Ltd., Hexagon House, Manchester 9
}

(Received 21 March 1950)

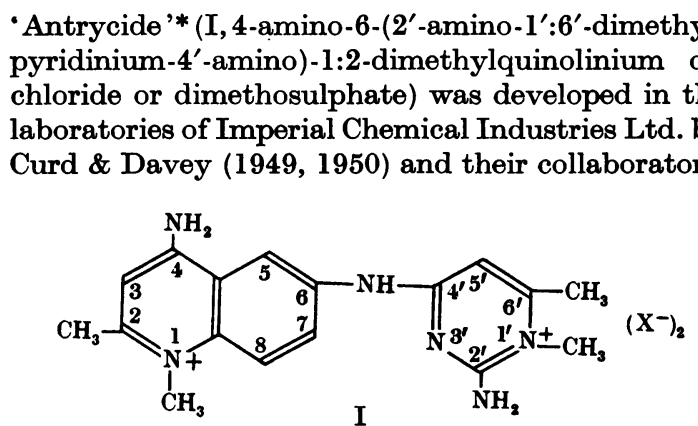

It has outstanding activity against numerous Trypanosoma species, notably $T$. congolense, in mice and cattle. Davey (1947) found that its action varied according to the form in which it was administered subcutaneously. Very soluble salts, for example the dimethosulphate ( $\mathrm{I}, \mathrm{X}^{-}=\mathrm{CH}_{8} \mathrm{SO}_{4}^{-}$), were more toxic than sparingly soluble salts, for example the dichloride $\left(\mathrm{I}, \mathrm{X}^{-}=\mathrm{Cl}^{-}\right)$, when these were given in large

* The name 'Antrycide' is a trade mark of Imperial Chemical (Pharmaceuticals) Ltd. amounts as dispersions. The prophylactic action of the dichloride, however, persisted longer than that of the dimethosulphate. If the subcutaneous reservoir of drug was removed, prophylactic activity was soon lost. These findings suggest that Antrycide, when given as a 'soluble' salt, may be more rapidly absorbed but less persistent than when given as an 'insoluble' salt, persistence possibly depending on slow seepage of Antrycide into the blood stream from the subcutaneous reservoir. Persistence owing to such an effect was demonstrated by Browning \& Gulbransen (1934) for a styrylquinoline derivative.

In order to examine these possibilities a method of determination was needed. It was clear that such a method must be very sensitive, since $1 \mu \mathrm{g}$. of Antrycide exerts a slight but definite therapeutic effect when administered subcutaneously to a mouse. Although several methods failed because of inadequate sensitivity, and some for other reasons as well, a short account of them will be given, as they may be applicable to other problems. A brief summary of the preferred method has already been published (Spinks, 1949). 


\section{EXPERIMENTAL AND RESULTS}

\section{Colour reactions}

Antrycide is colourless, and although it fluoresces blue in ultraviolet light the fluorescence is very weak. Initially, therefore, colorimetric methods were sought. Three main possibilities of chemical reaction were studied: (i) hydrolysis to give a diazotizable 6-aminoquinoline, comparable to the hydrolysis of 2-arylaminopyrimidines described by Spinks \& Tottey (1946); (ii) reaction with dimethylaminobenzaldehyde to give a styrylquinoline; (iii) reaction with the usual photosensitizer intermediates to give a cyanine dye. None of these reactions gave promising results. Hydrolysis of Antrycide was found by Curd (1947) to remove the two amino groups; very drastic conditions were necessary to give further breakdown. Styrylquinoline and cyanine-dye formation failed to occur under the varied conditions tried. Experiments with model compounds showed that this was due to the presence of the amino group in position 4 of the quinoline nucleus. Absence of this group led to facile reactivity. The possibility of converting it to hydroxyl by hydrolysis and then using the cyanine or styrylquinoline reaction was tried, but abandoned after preliminary tests on hydrolysates had given negative results, and after the 4-hydroxy compound itself had been shown not to react. Reaction of the parent compound with cyanogen bromide and various amines was also tried, but the yellow colours formed were very feeble, as were those obtained on attempted coupling with diazonium salts.

Failure to obtain chemical colour reactions directed attention to the possibility of using 'physical' colour reactions instead. Methods of determining organic bases by forming solvent-soluble salts with coloured acids have been introduced by Prudhomme $(1938,1940)$ and Auerbach (1943), and extended by many other workers, particularly Brodie (Brodie \& Udenfriend, 1945; Brodie, Udenfriend \& Dill, 1947). The principle of these methods is salt formation by the base with an acid dye at such a pH that the salt is soluble, and the excess acid insoluble, in an extracting solvent. The base can thus be determined in the solvent by colorimetry. Prudhomme $(1938,1940)$ used eosin, Auerbach (1943) (cf. Marshall \& Rogers, 1945; King, Wootton \& Gilchrist, 1946) bromophenol blue and bromothymol blue, and Brodie \& Udenfriend (1945) and Brodie et al. (1947) methyl orange. Another type of physical method has been developed by Gage, Rose \& Scott (1948) for suramin (Antrypol (Bayer, 205, 3:3' -ureidobis [8-(3-benzamido- $p$-toluido)1:2:5-naphthalenetrisulphonic acid]). They found that addition of suramin to styrylquinoline solutions gave a marked colour change which can be utilized for the estimation of suramin.

Such reactions have been investigated with Antrycide. Tests were made with about thirty acid dyes, including phenolphthaleins, sulphonphthaleins, azonaphthalenesulphonic acids, azobenzenesulphonic acids, and azostilbenesulphonic acids, and each dye-Antrycide mixture was shaken with ethylene dichloride. No salt passed into ethylene dichloride, and only one dye gave a marked colour change. This was brilliant yellow, stilbene-2:2'-disulphonic acid4:4'-bisazophenol, solutions of which in aqueous $\mathrm{Na}_{2} \mathrm{CO}_{3}$ changed from orange to red on adding Antrycide. A red precipitate was slowly deposited. Investigation of this colour change along the lines described by Gage et al. (1948) for suramin and 2-p-dimethylaminostyryl-6-acetamido- quinoline methochloride ( $S Q 24$ ) showed that it did not occur in very dilute solution, or in the presence of plasma. Several related dyes were synthesized by coupling tetrazotized 4:4'-diaminostilbene-2:2'-disulphonic acid with naphthols and dimethylaniline, but none gave as marked a colour change as brilliant yellow; however, the $\alpha$-naphthol dye ('dye $\alpha$ '), gave a highly insoluble salt. One other dye, congo red, also forms a highly insoluble salt; on shaking the dye-Antrycide mixture with ethylene dichloride the salt forms a lake at the interface. This phenomenon was further investigated using various solvents, and it was found that butanol dissolves the excess congo red completely, the salt remaining undissolved at the interface. This behaviour is roughly the reverse of that utilized in the development of the dye methods reviewed earlier. It was made the basis of a method of determining Antrycide in ordinary aqueous solution.

\section{Colorimetric determination (congo red method)}

To $1 \mathrm{ml}$. of an aqueous solution of Antrycide containing 0-10 $\mu$ g., add $1 \mathrm{ml}$. of a $3 \mathrm{mg}$. $/ 100 \mathrm{ml}$. solution of congo red WS (Imperial Chemical Industries Ltd.), $1 \mathrm{ml}$. of $0.5 \mathrm{M}$ phosphate buffer, $\mathrm{pH} \mathrm{7,} \mathrm{and} 1 \mathrm{ml}$. of butanol, and shake vigorously for $2 \mathrm{~min}$. Allow to stand for $2 \mathrm{~min}$. and transfer the upper layer to a colorimeter cell. Read the extinction coefficient against pure butanol as blank, using a green filter. The extinction coefficient decreases with increasing concentrations of Antrycide.

This method failed when applied directly to plasma, because the excess dye, instead of passing into butanol, completely laked with protein at the interface. It failed also with dilute aqueous solutions of more than about $7 \mathrm{ml}$. in volume, and therefore could not be applied to proteinfree plasma filtrates or to eluates from Decalso columns. Preliminary hydrolysis of plasma proteins by trypsin, pepsin, acid and alkali was tried, but gave most unpromising results.

\section{Colorimetric determination (suramin method)}

Since Antrycide reacted so readily with acid dyes it was suggested to the author by Mr J. C. Gage that it might combine strongly with suramin and thereby prevent discharge by the latter of the red colour of SQ 24 (Gage et al. 1948). This was found to occur, and the following method was developed.

To $1 \mathrm{ml}$. of an aqueous solution containing 0-10 $\mu \mathrm{g}$. of Antrycide, add $1 \mathrm{ml}$. of a $2 \mathrm{mg} . / 100 \mathrm{ml}$. solution of suramin, and $1 \mathrm{ml}$. of $0 \cdot 2 \mathrm{M}$-phosphate, $\mathrm{pH} 7$. Mix well and allow to stand for $5 \mathrm{~min}$. Add $1 \mathrm{ml}$. of a $12.5 \mathrm{mg} . / 100 \mathrm{ml}$. solution of $S Q 24$. Read the extinction coefficient against distilled water in a colorimeter or spectrophotometer using a filter or slit transmitting at $505 \mathrm{~m} \mu$. A standard curve is also constructed using known amounts of Antrycide. Most free $S Q 24$ is present when Antrycide concentrations are highest. Extinction coefficients at $505 \mathrm{~m} \mu$. therefore increase with increasing concentration of Antrycide.

This method failed in the presence of plasma, but dilution did not affect the results, except that sensitivity was reduced, so that it could be applied to plasma filtrates. Its sensitivity was then too low for the analysis of Antrycide in plasma from dosed animals. 
Various other colorimetric methods were developed, but will not be described in detail. One involved chromatography on alumina of mixed solutions of Antrycide and dye $\alpha$. The salt separated out at the top of the column, was washed free of excess dye with water, and was then eluted with ethanolic $\mathrm{KOH}$. A related method involved shaking similar solutions of dye and Antrycide with kieselguhr. The salt came down with the kieselguhr on centrifuging and was washed and eluted as in the chromatographic experiments. Both methods failed in the presence of plasma, or when less than 2-5 $\mu$ g. of Antrycide were present.

\section{Fluorescence of Antrycide}

Using the Spekker fluorimeter 5-50 $\mu \mathrm{g}$. of Antrycide could be determined in $10 \mathrm{ml}$. of water, using the Coleman fluorimeter (model $12 \mathrm{~A}$ ) $0 \cdot 5-10 \mu \mathrm{g}$. in $10 \mathrm{ml}$. The Coleman fluorimeter had the further advantage that the plot of concentration against galvanometer reading was a straight line.

The colour of the fluorescence was first investigated. An approximate fluorescence spectrum was constructed by reading the fluorescence intensity of a $200 \mu \mathrm{g} . / \mathrm{ml}$. solution

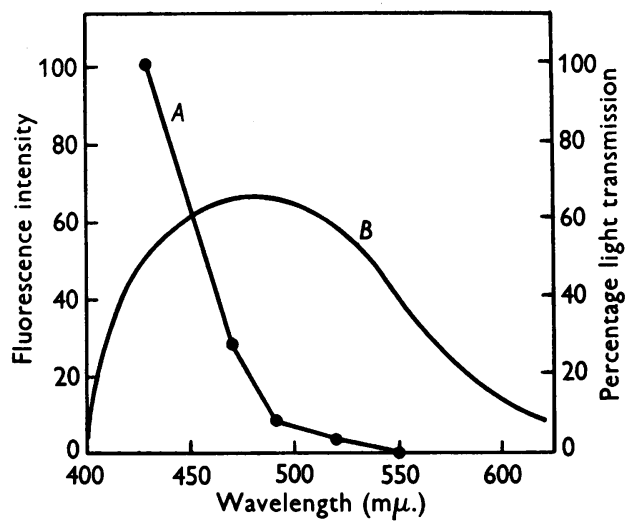

Fig. 1. Approximate fluorescence spectrum of Antrycide in buffer, pH $3(A)$, and transmission of filter $\mathrm{PCl}(B)$.

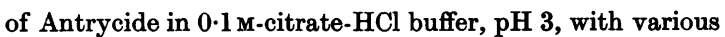
Ilford Spectrum filters in the fluorimeter. The results are given in Fig. 1. They have been adjusted to compensate for the different transmissions of the filters. The fluorescence was maximal at the lowest wavelengths it was possible to use. Of the available filters the Coleman filter PCl gave the highest sensitivity when used in conjunction with ultraviolet filter B1S. The transmission of filter PCl is shown in Fig. 1.

The variation of fluorescence intensity with $\mathrm{pH}$ was investigated using as solvents $0 \cdot 1 \mathrm{M}$-citrate- $\mathrm{HCl}, 0 \cdot 1 \mathrm{M}$-phosphate and $0 \cdot 1 \mathrm{~m}$-glycine-NaOH buffers (Fig. 2). The glycine$\mathrm{NaOH}$ buffers gave a curve which was not continuous with that given by the others. An effect of electrolytes on the fluorescence may therefore be suspected, although it is probably only slight. Since fluorescence was maximal at pH 3 acid protein precipitants were examined. Fig. 3 shows the fluorescence intensity of Antrycide added to $(a)$ dilute trichloroacetic acid (TCA), (b) a TCA filtrate from normal plasma, and (c) plasma before precipitation with TCA. The results showed that substances present in the plasma increased the fluorescence of Antrycide, and that loss of about $30 \%$ of the Antrycide occurred during the precipitation of plasma proteins with TCA. These two opposite effects

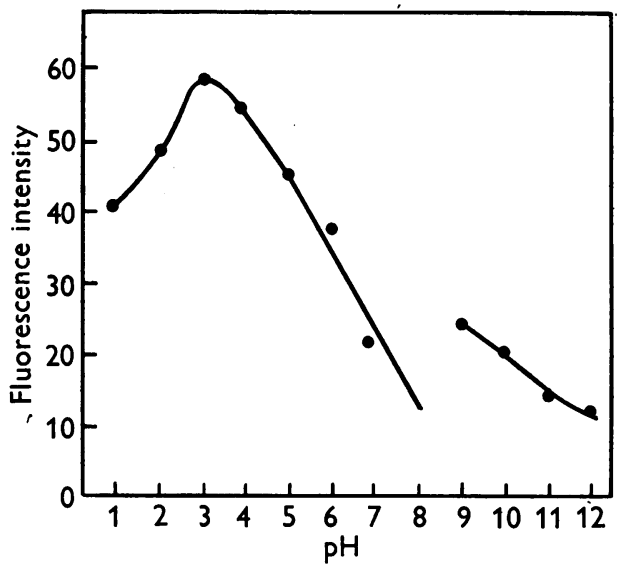

Fig. 2. Effect of $\mathrm{pH}$ on the fluorescence of Antrycide. pH 1-4, 0.1 M-citrate-HCl; $\mathrm{pH} 5-8,0.1 \mathrm{~m}$-phosphate; pH 9-12, 0.1 M-glycine-NaOH.

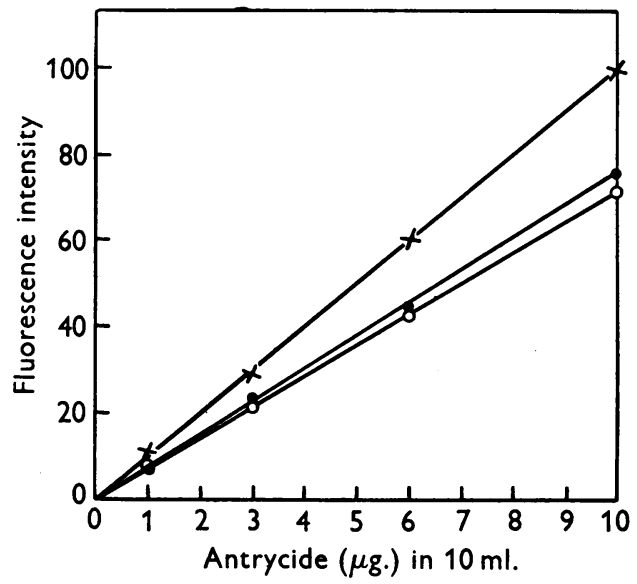

Fig. 3. Fluorescence intensity of Antrycide; in TCA, added to a TCA filtrate of normal serum, $x-x$; added to serum before precipitation with TCA, $\mathrm{O}-\mathrm{O}$.

showed that it would not be possible to determine Antrycide using aqueous standards, and the procedure used by Brodie \& Udenfriend (1943) for the determination of quinine was adopted; that is, a sample of normal plasma was obtained from an experimental animal before dosing and used in the preparation of a blank and standard, as described below. No attempt was made to buffer the TCA filtrate to $\mathrm{pH} \mathrm{3}$, as this only raised the fluorescence intensity by about $10 \%$. A description of the method follows. 


\section{Direct fluorimetric method}

To three tubes, labelled $B, S, U$, add, respectively, $1 \mathrm{ml}$. of normal plasma, $1 \mathrm{ml}$. of normal plasma, and $1 \mathrm{ml}$. of plasma to be analysed. Add $9 \mathrm{ml}$. of water to $B$ and $U$, and $8 \mathrm{ml}$. of water and $1 \mathrm{ml}$. of a $1 \mathrm{mg} . / 100 \mathrm{ml}$. aqueous solution

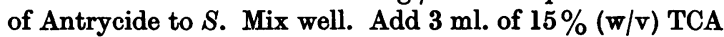
to each tube, mix well, and allow to stand for $10 \mathrm{~min}$. Centrifuge for $20 \mathrm{~min}$. at $3000-4000 \mathrm{rev} . / \mathrm{min}$. and transfer the upper layers to fluorimeter cuvettes. With solution $B$ in the instrument, and using filter combination B1S, PCl, adjust the galvanometer to zero, and then take the readings of solutions $S$ and $U$. If these readings are $s$ and $u$ respectively, the concentration of Antrycide in the unknown is $u / 8 \mathrm{mg} . / 100 \mathrm{ml}$. Recoveries of known amounts of Antrycide are shown in Table 1.

\section{Table 1. Recovery of Antrycide from plasma by the direct fuorimetric method}

$\begin{array}{ccc}\begin{array}{c}\text { Added } \\ (\mu \mathrm{g} .)\end{array} & \begin{array}{c}\text { Found } \\ (\mu \mathrm{g} .)\end{array} & \begin{array}{c}\text { Recovery } \\ (\%)\end{array} \\ 1 & 1 \cdot 09 & 109 \\ 2 & 1 \cdot 83 & 91 \\ 3 & 3 \cdot 58 & 119 \\ 3 & 2 \cdot 66 & 89 \\ 3 & \mathbf{3} \cdot 07 & 102 \\ 5 & 5 \cdot 21 & 104 \\ 5 & 4 \cdot 80 & 96 \\ 6 & 5 \cdot 99 & 100 \\ 7 & 6 \cdot 20 & 89 \\ 7 & 7 \cdot 33 & 105 \\ & & \text { Mean } 100\end{array}$

The use of this method for the determination of Antrycide in the plasma of dosed animals showed that it would measure Antrycide if the latter had been given intravenously or as a 'soluble' salt subcutaneously, but not if it had been given as an 'insoluble' salt subcutaneously. At best it would only measure the earlier concentrations up to about $3 \mathrm{hr}$. after the administration of 5 or $10 \mathrm{mg} . / \mathrm{kg}$. Efforts were therefore made to increase the sensitivity, mainly in two ways. First, the effect of the reagent used by Auerbach \& Eckert (1944) to potentiate the fluorescence of mepacrine was examined; secondly, the possibility of concentrating Antrycide by adsorption and elution techniques was tried. The Auerbach reagent contains caffeine, sodium benzoate, ethanol and ethanolamine. When added to solutions of Antrycide in TCA it increased the intensity of fluorescence about twice, but the increase was too small to be of any value. Tests with ion-exchange columns showed that Antrycide could be concentrated from a large volume of water or serum by passing it through a Decalso column. Antrycide was retained, and part of it could subsequently be eluted with $25 \%$ (w/v) $\mathrm{KCl}$ in $0.2 \mathrm{~N}-\mathrm{HCl}$. So far, unfortunately, no base-exchange resin or eluent tested has allowed quantitative elution of the Antrycide, which appeared to be very firmly retained by each resin.

\section{Indirect fluorimetry}

While these experiments were in progress the author's colleague, Dr J. Raventòs, had been examining the determination of dextro-tubocurarine chloride, partly along lines indicated by the author's experience with Antrycide. $\mathrm{He}$ found that dextro-tubocurarine chloride, also a complex quaternary salt, behaved very much like Antrycide in that salts formed with acid dyes were insoluble in benzene and ethylene dichloride. However, with 'bluish' eosin it gave a salt which could be separated from excess eosin by shaking at $\mathrm{pH} 7$ with $\mathrm{CHCl}_{8}$ containing $15 \%(\mathrm{v} / \mathrm{v})$ of butanol; the salt was feebly coloured and, in the extracting solvent, feebly fluorescent. Raventòs's technique was tried with Antrycide and it was found that the salt of Antrycide and 'yellowish' eosin was very strongly fluorescent in $\mathrm{CHCl}_{3}$-butanol. The conditions of the method were therefore examined in detail.

The approximate fluorescence spectrum was established as described for Antrycide itself, using a $\mathrm{CHCl}_{3}$-butanol solution containing the eosin salt from $4 \mu \mathrm{g}$. of Antrycide in $12 \mathrm{ml}$. This spectrum is shown in Fig. 4. Fluorescence intensity was highest at $550-580 \mathrm{~m} \mu$. in conformity with the

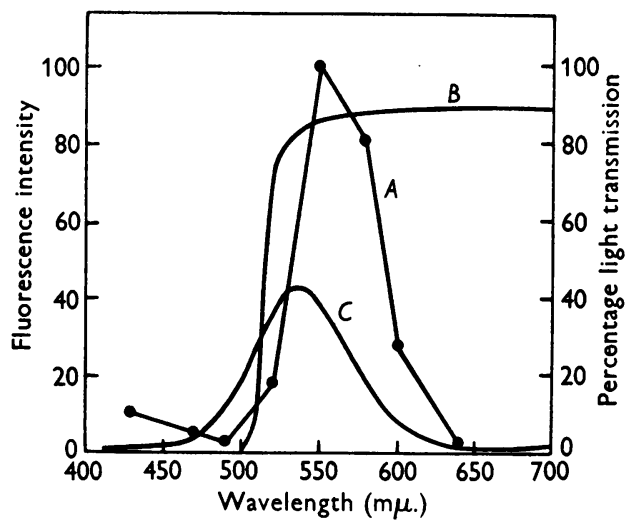

Fig. 4. Approximate fluorescence spectrum of an Antrycideeosin solution in $\mathrm{CHCl}_{3}$-butanol $(A)$, compared with the light transmission of filters Coleman PC9 $(B)$ and Chance OG $2(C)$.

greenish-yellow colour. Two filters were used in subsequent experiments, a Coleman yellow filter, PC9, and a Chance green filter OG 2. The transmittance of these filters is shown in Fig. 4. The yellow filter was used with ultraviolet filter B IS (a combination subsequently referred to as $H$, for high sensitivity) and the green with ultraviolet filter B 1 (combination $L$ for low sensitivity). Bl transmits mainly the $365 \mathrm{~m} \mu$. band, like B $1 \mathrm{~S}$, but incorporates a screen which reduces the amount of incident light. Filter combination $H$ was about ten times as sensitive as combination $L$. The use of both permitted the determination of $0.01-4 \mu \mathrm{g}$. of Antrycide without diluting the final solutions. The Coleman yellow-green filter PC9 A gave slightly higher sensitivity than PC9, but the amount of blue fluorescence passed by it was so much greater as to reduce the accuracy of determination, chance contamination usually leading to increased blue fluorescence of the final extracts. The plasma blank was also increased when filter PC9 A was used. This blank is usually 0-8 $\mu$ g./l. with combination $H$. It is higher with combination $L$, but because $L$ is used to determine very high concentrations the difference may be neglected.

Figs. 5-7 show the effect, on the fluorescence intensity, of variations in the amount of eosin used, the proportion of butanol in the solvent mixture, and the $\mathrm{pH}$. The conditions giving maximal intensity were incorporated in the method described below, except that $20 \%(\nabla / v)$ of butanol was used because higher concentrations increased the extraction of 
interfering materials from plasma filtrates, and caused the formation of emulsions. The superiority of saturated $\mathrm{NaHCO}_{3}$ to a $0.5 \mathrm{M}$-buffer of the same $\mathrm{pH}$ was ascribed to a salting-out effect. During these experiments it was discovered that the eosin available ('Eosin, water-soluble, yellowish', G. T. Gurr, London, S.W.6) required purification to give the best results. 'Bluish' eosin, dichlorofluorescein and other dyes gave results no better than those with 'yellowish' eosin. Fluorescein did not react under the conditions used.

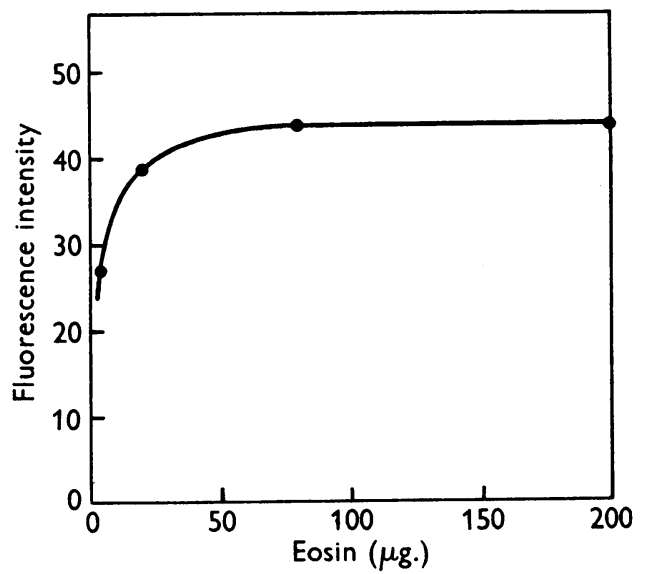

Fig. 5. Effect of varying the amount of eosin on the extraction of the Antrycide-eosin complex into $\mathrm{CHCl}_{3}$ butanol.

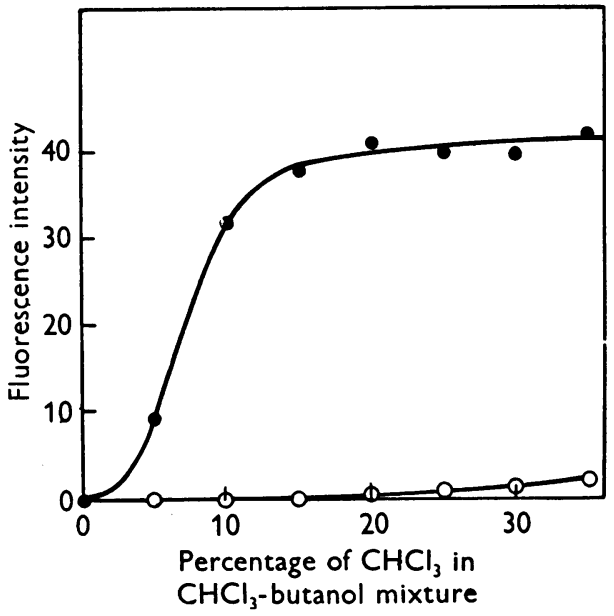

Fig. 6. Effect of composition of $\mathrm{CHCl}_{3}$-butanol mixtures on the extraction of eosin-Antrycide from saturated $\mathrm{NaHCO}_{3}$ : -O, reading of extract against corresponding blank; $\mathrm{O}-\mathrm{O}$, reading of blank against $\mathrm{CHCl}_{3}$.

Plasma when shaken with eosin, $\mathrm{NaHCO}_{3}$ and solvent mixture gave a strongly fluorescing extract. The fluorescence, although blue with no apparent trace of green, was equivalent to that of several hundred $\mu \mathrm{g}$. of Antrycide/l. Protein precipitation methods were therefore examined. It was found that when a solution of Antrycide in dilute TCA was approxi- mately neutralized before adding the eosin reagent and solvent, the results were satisfactory if the volume of the aqueous phase did not exceed about $15 \mathrm{ml}$. Beyond this limit emulsion formation became troublesome. Since it was hoped to use several $\mathrm{ml}$. of plasma and thereby improve sensitivity, the recovery of Antrycide was examined by precipitation at low dilutions. Mean recoveries at overall dilutions of $1 / 3 \cdot 5,1 / 6$ and $1 / 10$ were 33,59 and $77 \%$, respectively. The last dilution was therefore adopted, although the volume limitation referred to above prevented the use of more than about $1.5 \mathrm{ml}$. of plasma. The following are the final conditions adopted.

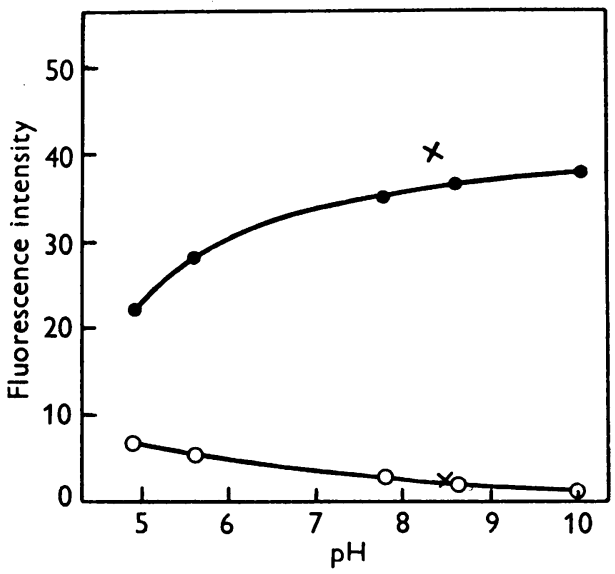

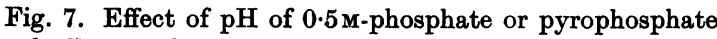
buffers on the extraction of the Antrycide-eosin complex into $\mathrm{CHCl}_{3}$-butanol: -0 , reading of extract against corresponding blank; $\mathrm{O}-\mathrm{O}$, reading of blank against $\mathrm{CHCl}_{3}$-butanol; $\times$, saturated $\mathrm{NaHCO}_{8}$.

\section{Indirect fluorimetric method for plasma}

Reagents. (1) Stock solution of eosin ('yellowish', watersoluble, $500 \mathrm{mg}$.), in saturated $\mathrm{NaHCO}_{3}$ (A.R., $500 \mathrm{ml}$.). This stock solution is purified by shaking with fresh lots of solvent mixture until the latter no longer removes coloured or fluorescent impurities. It is stable in the dark. (2) Buffered eosin reagent. The stock solution is diluted $1 / 25$ with saturated $\mathrm{NaHCO}_{3}$. It is stable in the dark. (3) Solvent mixture. Dilute $200 \mathrm{ml}$. of redistilled $n$-butanol to $1000 \mathrm{ml}$. with $\mathrm{CHCl}_{3}$ (B.P.). (4) N-Sodium hydroxide (A.R.). (5) $15 \%$ (w/v) trichloroacetic acid (A.R.). (6) Antrycide stock standard solution, $100 \mathrm{mg}$. $/ 100 \mathrm{ml}$. (referred toion). Dissolve $134.5 \mathrm{mg}$. of the dichloride dihydrate in water and dilute to $100 \mathrm{ml}$. (7) Antrycide working standard, $0.05 \mathrm{mg} . / 100 \mathrm{ml}$. Dilute the stock standard when required.

Special apparatus. Coleman or similar electronic fluorimeter.

Procedure. Dilute $1.2 \mathrm{ml}$. of plasma to $10 \mathrm{ml}$. with distilled water. Add $2 \mathrm{ml}$. of $15 \%$ (w/v) TCA; mix well, allow to stand for $10 \mathrm{~min}$., and centrifuge at about $2000 \mathrm{rev} . / \mathrm{min}$. for $15 \mathrm{~min}$. Transfer $10 \mathrm{ml}$. of the upper layer to a $60 \mathrm{ml}$. glass-stoppered bottle, and add $1 \mathrm{ml}$. of $\mathrm{N}-\mathrm{NaOH}, 2 \mathrm{ml}$. of buffered eosin reagent, and $12 \mathrm{ml}$. of solvent mixture, delivered from a burette. Shake vigorously for $3 \mathrm{~min}$., and allow to stand until the lower layer is clear. Remove the lower layer by means of a pipette provided with a rubber 
teat, and filter it through Whatman no. 1 or similar semi-fine paper, into a Coleman fluorimeter cuvette. Read the fluorescence against a blank and standards as described below.

Blank and standards. Pipette 0, 0.1, 0.2, 0.4, 1.0, 2 and $5 \mathrm{ml}$. of Antrycide working standard into $30 \mathrm{ml}$. bottles. Add to each $2 \mathrm{ml}$. of buffered eosin reagent and $12 \mathrm{ml}$. of solvent mixture. Shake vigorously for 3 min., allow to stand, and filter the lower layers into fluorimeter cuvettes as described above. The unknowns are read against blank and standards as follows. Using filter combination $H$ and the full sensitivity setting of the instrument adjust the galvanometer needle to zero with the blank ( $0 \mu \mathrm{g}$. of Antrycide) in position. Then read the fluorescence intensity of unknowns and standards. Retain those samples that read higher than 100 for examination by the 'low sensitivity' technique. A reading of 100 is equivalent to about $0.4 \mu \mathrm{g}$. of Antrycide ion. Now substitute filter combination $L$ for $H$. Re-adjust the zero setting of the galvanometer, retaining the full sensitivity setting, and read all samples. A reading of 100 is equivalent to about $4 \mu \mathrm{g}$. of Antrycide. As a plasma level of more than 5-6 $\mu \mathrm{g} . / \mathrm{ml}$. is usually lethal it is not likely that any unknown plasma sample will give a reading higher than 100. If one does, it and the standards are read again using a sensitivity setting sufficiently low to reduce the reading of the unknown to 100. Standard curves are then constructed from the readings of the standards, and the amounts of Antrycide found in unknowns are read from the appropriate curve. The amount found is multiplied by a factor of $1 \cdot 3$ to allow for the low recovery of Antrycide from plasma (Table 2).

Notes. In order to recognize the existence of concentrations of Antrycide lower than $20 \mu \mathrm{g}$./l. (which give a reading of about 5 on the galvanometer), it is necessary to

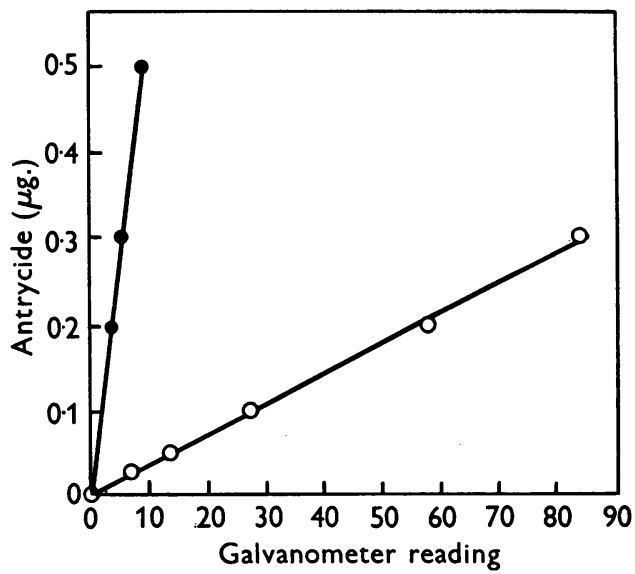

Fig. 8. Standard curves for the indirect fluorimetric determination of Antrycide, using filters B1 and OG 2 (O), or B 1 S and PC9 (O), in the Coleman fluorimeter.

adopt rigid precautions to ensure apparatus and reagent cleanliness. It has been the practice to check these precautions by including a 'water analysis' in each series of determinations. Water $(1.2 \mathrm{ml}$.) is analysed exactly as plasma. This water analysis should never give a reading of more than 1 on the galvanometer (equivalent to approximately $0.003 \mu \mathrm{g}$. of Antrycide). The standard curves are usually straight lines (Fig. 8). However, occasional divergences have been observed, and full standard curves are constructed for each series of determinations. It is estimated that concentrations down to $40 \mu \mathrm{g}$./l. can be measured with satisfactory precision, and concentrations from 20 to $40 \mu \mathrm{g}$./l. approximately. Measurements of 5-10 $\mu \mathrm{g}$./1. should be recorded as 'traces'. These estimates of sensitivity apply only to the fluorimeter specified and then only when the latter is in optimal condition.

Recoveries of Antrycide from plasma are shown in Table 2.

\section{Table 2. Recovery of Antrycide from plasma by the indirect fluorimetric method}

$\begin{array}{lcr}\begin{array}{c}\text { Added } \\ (\mu \mathrm{g} .)\end{array} & \begin{array}{c}\text { Found } \\ (\mu \mathrm{g} .)\end{array} & \begin{array}{r}\text { Recovery } \\ (\%)\end{array} \\ 0 \cdot 005 & (0 \cdot 008) & (160) \\ 0 \cdot 01 & (0 \cdot 008) & (80) \\ 0 \cdot 015 & (0 \cdot 012) & (80) \\ 0 \cdot 02 & (0 \cdot 020) & (100) \\ 0 \cdot 03 & (0 \cdot 028) & (93) \\ 0 \cdot 04 & 0 \cdot 034 & 85 \\ 0 \cdot 04 & 0 \cdot 029 & 72 \\ 0 \cdot 05 & 0 \cdot 042 & 84 \\ 0 \cdot 08 & 0 \cdot 060 & 75 \\ 0 \cdot 08 & 0 \cdot 060 & 75 \\ 0 \cdot 10 & 0 \cdot 085 & 85 \\ 0 \cdot 12 & 0 \cdot 099 & 82 \\ 0 \cdot 15 & 0 \cdot 124 & 83 \\ 0 \cdot 20 & 0 \cdot 150 & 75 \\ 0 \cdot 20 & 0 \cdot 166 & 83 \\ 0 \cdot 25 & 0 \cdot 192 & 77 \\ 0 \cdot 28 & 0 \cdot 204 & 73 \\ 0 \cdot 28 & 0 \cdot 204 & 73 \\ 0 \cdot 35 & 0 \cdot 262 & 75 \\ 0 \cdot 40 & 0 \cdot 274 & 68 \\ 0 \cdot 40 & 0 \cdot 288 & 72 \\ 0 \cdot 50 & 0 \cdot 391 & 78 \\ 1 \cdot 00 & 0 \cdot 743 & \mathbf{7 4} \\ 2 \cdot 00 & 1 \cdot 64 & 82 \\ 2 \cdot 00 & 1 \cdot 42 & 71 \\ 3 \cdot 00 & 2 \cdot 28 & 76 \\ & & 77 * \\ * & \text { Excluding } & \\ & \text { results in parentheses. } & \end{array}$

\section{Application to other biological materials}

The determination of Antrycide in blood and tissue was first attempted using the conditions outlined for plasma. When blood was precipitated at $1 / 10$ dilution the mean recovery was $36 \%$. Liver (1.2 g.) gave a recovery which varied from 3 to $20 \%$ according to the amount of drug present. It was eventually found that mean recoveries of the order of $70 \%$ were attained if $0.2 \mathrm{~g}$. of tissue or $0.4 \mathrm{ml}$. of blood were used in place of $1.2 \mathrm{ml}$. of plasma in the procedure already described. Normal tissues give readings equivalent to $0-0 \cdot 1 \mathrm{mg}$. of Antrycide $/ \mathrm{kg}$.

Determination in urine is simpler since it does not involve a protein-precipitation procedure. However, normal urine gives a rather high blank. This blank is due almost entirely to extraction of fluorescing materials present as such in the urine, not to extraction of eosin complexes. The method described 
below allows for this by including a blank prepared by extracting a second sample of urine with solvent mixture in the absence of eosin.

Add to $0 \cdot 1-4 \mathrm{ml}$. of urine $2 \mathrm{ml}$. of buffered eosin reagent and $12 \mathrm{ml}$. of solvent mixture. Shake for $3 \mathrm{~min}$. and clarify the extract as described above. Let the fluorescence of the extract be equivalent to $a \mu \mathrm{g}$. of Antrycide. Prepare a second extract by adding $2 \mathrm{ml}$. of saturated $\mathrm{NaHCO}_{3}$ and $12 \mathrm{ml}$. of solvent mixture to the same volume of urine, and treating as the earlier sample. If the fluorescence of this blank is equivalent to $b \mu \mathrm{g}$. of Antrycide, the amount of Antrycide in the urine is $(a-b) \mu \mathrm{g}$. It is particularly important to use a visual filter (e.g. PC9), letting little or no light pass below $500 \mathrm{~m} \mu$. as the blank fluorescence is mainly in this range; $a$ and $b$ are usually identical in normal rabbit urine. Recoveries from urine are shown in Table 3.

\section{Table 3. Recovery of Antrycide from urine by} the indirect fluorimetric method

$\begin{array}{ccc}\begin{array}{c}\text { Added } \\ (\mu \mathrm{g} .)\end{array} & \begin{array}{c}\text { Found } \\ (\mu \mathrm{g} .)\end{array} & \begin{array}{c}\text { Recovery } \\ (\%)\end{array} \\ 0 \cdot 04 & 0.042 & 105 \\ 0 \cdot 06 & 0.062 & 103 \\ 0 \cdot 10 & 0 \cdot 097 & 97 \\ 0 \cdot 14 & 0 \cdot 150 & 107 \\ 0 \cdot 20 & 0.187 & 93 \\ 0 \cdot 20 & 0.215 & 107 \\ 0.40 & 0.403 & 101 \\ & & \text { Mean } 102\end{array}$

\section{Specificity of the method}

The specificity of the indirect fluorimetric method was examined by extracting $10 \mu \mathrm{g}$. of various compounds and $2 \mathrm{ml}$. of buffered eosin reagent with $12 \mathrm{ml}$. of solvent mixture. The fluorescence of the extract was read against Antrycide standards and expressed in terms of $\mu \mathrm{g}$. of Antrycide. The results are shown in Table 4.

\section{DISCUSSION}

The unexpectedly high degree of specificity of the indirect fluorimetric method, particularly as regards compounds as closely related to Antrycide as the corresponding quinolone and pyridone, and a possible hydrolysis product, 4:6-diaminoquinaldine methochloride, suggests that the method might discriminate between Antrycide and its metabolites. No rigid appraisal of this aspect of specificity has been made, although it has been shown that direct and indirect fluorimetric methods give results of the same order when plasma of dosed animals is analysed. The specificity of the method is partly conferred by the choice of experimental conditions. For example, the use of higher concentrations of eosin increased the reaction of dextro-tubocurarine chloride.

Experience with the method in the analysis of plasma has shown that it is not yet sensitive enough to measure suppressive concentrations of Antrycide. Thus, after the administration of $5 \mathrm{mg}$. of Antrycide chloride/kg. subcutaneously to rabbits the plasma concentration had fallen so low after $24 \mathrm{hr}$. that it could not be accurately measured. In calves the same dose gave a maximum level of not more than $40 \mu \mathrm{g} . / 1$., which was only just measurable. Since Antrycide chloride given in these amounts exerts a well defined prophylactic action for many months, it follows that the suppressive level must be extremely small, probably below $1 \mu \mathrm{g}$./l., and therefore outside the range of any method of determination so far

\section{Table 4. Specificity of indirect fuorimetric method}

(The reactivity of $10 \mu \mathrm{g}$. of each of the bases is expressed as equivalent to that of $x \mu \mathrm{g}$. of Antrycide.)

\begin{tabular}{ll}
\multicolumn{1}{c}{ Base } & $x(\mu \mathrm{g})$. \\
Quinine & $0 \cdot 01$ \\
'Paludrine' & $0 \cdot 04$ \\
Antrycide-4-quinolone & $0 \cdot 35^{*}$ \\
Antrycide-2'-pyridone & $0 \cdot 05^{*}$ \\
Antrycide-2':4-dione & $0 \cdot 05^{*}$ \\
Antrycide-monoquaternary analogue & $8 \cdot 10$ \\
(pyridine ring) & \\
Antrycide-monoquaternary analogue & $6 \cdot 30$ \\
(quinoline ring) & \\
Mepacrine & $2 \cdot 00 \dagger$ \\
4:6-Diaminoquinaldine (DAQ) & $1 \cdot 30 \dagger$ \\
4:6-DAQ-methochloride & $0 \cdot 30$ \\
dextro-Tubocurarine chloride & $0 \cdot 1$ \\
'Dimidium' bromide & $0 \cdot 2$ \\
'Cetarlon' & $0 \cdot 05$ \\
N(CH (C) $_{4}$ Br & 0 \\
N(C H $\left._{5}\right)_{4}$ Br & 0 \\
Choline bromide & 0 \\
Emetine & $0 \cdot 02$ \\
Strychnine & 0 \\
Atropine & 0 \\
Morphine & 0
\end{tabular}

* These compounds contain potential hydroxyl groups in place of amino groups in the positions indicated (see formula on p. 299).

$\dagger$ The fluorescence is probably due to extraction of bases or bicarbonates, not eosin complexes.

devised. The obvious methods of improving sensitivity will be tried. These are a search for a protein precipitant which will permit the use of larger amounts of plasma in the indirect method, and further attempts to concentrate Antrycide by adsorption on ion-exchange columns. However, it is doubtful whether either technique, even if developed to the utmost extent predictable at present, would result in more than a tenfold increase in sensitivity. The ultimate object, it is thought, should be the preparation of Antrycide containing radioactive carbon: for example, in one or both of the quaternary methyls. The limitation of low sensitivity applies only to plasma. Antrycide is localized in liver and kidney and can readily be detected in them, and in urine, for several weeks after admini stration. The method has also given valuable results in the examination of curative, as distinct from suppressive, plasma concentrations, and in the comparison of different salts. The findings will be published elsewhere. 


\section{SUMMARY}

1. Antrycide has been determined by reaction with eosin to give a highly fluorescent salt which can be separated from excess eosin by extraction into a mixture of chloroform and butenol.

2. The method measures down to $40 \mu \mathrm{g}$. of Antrycide/l. of plasma with satisfactory accuracy, and $20 \mu \mathrm{g}$./. approximately.

3. The method has a considerable degree of specificity, in that most other tertiary and quaternary bases examined did not react.
4. It can be applied to tissues and urine as well as plasma.

5. A less sensitive method suitable for plasma involves measuring the weak blue fluorescence of Antrycide itself.

6. Two colorimetric methods, suitable only for aqueous solutions, are briefly described.

The author is indebted to Mrs E. Powell, Mrs R. B. Horton and $\mathrm{Mr} \mathrm{A}$. M. Barlow for valuable technical assistance, and to Dr D. G. Davey and Dr J. Raventòs for much helpful discussion.

\title{
REFERENCES
}

Auerbach, M. E. (1943). Industr. Engng Chem. (Anal. ed.), $15,492$.

Auerbach, M. E. \& Eckert, H. W. (1944). J. biol.Chem. 154, 597.

Brodie, B. B. \& Udenfriend, S. (1943). J. Pharmacol.78, 154.

Brodie, B. B. \& Udenfriend, S. (1945). J.biol. Chem. 158, 705.

Brodie, B. B., Udenfriend, S. \& Dill, W. (1947). J.biol.Chem. $168,335$.

Browning, C. H. \& Gulbransen, R. (1934). J. Path. Bact. $39,75$.

Curd, F. H. S. (1947). Private communication.

Curd, F. H. S. \& Davey, D. G. (1949). Nature, Lond., 163, 89.
Curd, F. H. S. \& Davey, D. G. (1950). Brit.J. Pharmacol. 5, 25.

Davey, D. G. (1947). Private communication.

Gage, J. C., Rose, F. L. \& Scott, M. (1948). Biochem. J. 42, 574.

King, E. J., Wootton, I. D. P. \& Gilchrist, M. (1946). Lancet, $1,886$.

Marshall, P. B. \& Rogers, E. W. (1945). Biochem. J. 39, 258.

Prudhomme, R. O. (1938). Bull. Soc. Path. exot. 31, 929.

Prudhomme, R. O. (1940). J. Pharm. Chim., Paris, (9), 1, 8. Spinks, A. (1949). Nature, Lond., 163, 954.

Spinks, A. \& Tottey, M. M. (1946). Ann.trop. Med. Parasit. 40, 101 .

\section{The Influence of Scurvy and Fall in Weight in Young Guinea Pigs on the Alkaline Phosphatase Content of the Serum and the Zones of Provisional Calcification}

\author{
By H. R. PERKINS ANd S. S. ZILVA (Member of the Scientific Staff, Medical Research Council) \\ Lister Institute, London, S.W. 1
}

(Received 29 March 1950)

Some years ago Robison and his collaborators (Robison, 1932), as a result of a series of brilliantly conceived and interpreted investigations, broke new ground by advancing some hypotheses on the function of phosphatases in the animal body, particularly in the process of ossification. These contributions led to an extension of the field of inquiry, thus attracting the attention of the clinical pathologist. In their pioneer work, Smith \& Maizels (1932) and Smith (1933) found, amongst other observations, that the plasma phosphatase of infants and young children suffering from acute scurvy was low, and that the enzyme concentration in the plasma rose on treatment. Similar observations were made by Scoz, Cattaneo \& Gabbrielli (1937), Todhunter \& Brewer (1940) and Shwachman and Gould (Shwachman, 1941; Gould \& Shwachman, 1941, 1943; Shwachman \& Gould, 1942) on young guinea pigs suffering from scurvy. Scurvy, however, is not the only condition responsible for a diminution in the phosphatase of the blood. The early experiments of Smith (1933) have already shown that several diseases associated with arrested growth, or with severe marasmus, such as coeliac disease, achondroplasia and cretinism, also produce such a fall in the blood phosphatase. Similarly, in prolonged arrested growth and in loss of weight a striking drop in the serum phosphatase can be observed in young guinea pigs (Watkins \& Zilva, unpublished results).

In growing guinea pigs maintained on a scorbutic diet the development of scurvy and fall in weight overlap, and it is therefore not easy to ascertain with any degree of certainty whether the observed fall in serum phosphatase is due to one or other of these causes. Todhunter \& Brewer (1940), in controlling their experiments, used the 'paired-feeding tech- 